\title{
The Role of Environmental Features of Parks in Activation of Recreational Activities in Leisure Time
}

\author{
${ }^{1}$ Karim Zohrevandian ${ }^{*}{ }^{2}$ Ali Bastami, ${ }^{3}$ Hossein Naderlu, ${ }^{2}$ Ali Mohammad Safania \\ ${ }^{1}$ Department of Physical Education and Sport Sciences, Tarbiat Modares University, Tehran, Iran. ${ }^{2}$ Department of \\ Physical Education and Sport Sciences, Science and Research Branch, Islamic Azad University, Tehran, Iran. \\ ${ }^{3}$ Department of Physical Education and Sport Sciences, Karaj Branch, Payam Noor University, Karaj, Iran.
}

\begin{abstract}
Background. The recreational use of urban spaces has increased significantly in recent years, due to a trend towards healthier lifestyles in which regular exercise plays a leading role. Examples include walking, running or biking, activities for which large urban green parks provide excellent conditions. These parks, located within the city, are intended for public use and include landscape features such as trees, shrubs, extended grassy areas, playgrounds or water bodies.

Objectives. The aim of this study was to investigate the role of environmental features of parks in activation of recreational activities.

Methods. 425 people of over 18 years living near to six urban and regional parks in Tehran included in the study. Data collection has been done through questionnaire (Bedimo-Rung, 2005; Kaczynski, 2007 and Cohen, 2007), and data analysis has been done through structural equations and multivariate regression.

Results. The research findings showed that the variables of design $(\mathrm{T}=2.84)$, green space $(\mathrm{T}=3.25)$, accessibility $(\mathrm{T}=2.17)$, Placement $(\mathrm{T}=3.18)$, beauty $(\mathrm{T}=2.04)$, traffic expectation $(\mathrm{T}=2.45)$, security $(\mathrm{T}=2.27)$, and management $(\mathrm{T}=2.35)$, have relation with attendance and attraction of users of parks for recreational activity.

Conclusion. Management of public green spaces leads to increased presence and attendance of elderlies and recreational activities by creating building natural symbols and social interaction. Increased security of environment and its equipment leads to increased welfare, elevated revenues and occupational status and increased attendance of individuals in parks.
\end{abstract}

KEY WORDS: Environmental Features, Parks, Recreational Activities, Leisure Time.

\section{INTRODUCTION}

Parks, recreational, welfare complexes and etc are part of social centers and urban open spaces that in leisure time, they are used by various age groups especially young people. Thus, they have significant role in health of society such that inattention and inefficiency of these spaces is usually considered serious problem for the city (1). The recreational use of urban spaces has increased significantly in recent years, due to a trend towards healthier lifestyles in which regular exercise plays a leading role (2). Leisure time is potentially one of the most important ways for facilitation of health, it is an area in which identify is constructed. People are seriously engaged in most recreational activities, men and women of all ages and from any

*. Corresponding Author:

Karim Zohrevandian

E-mail: k.zohrevand8098@gmail.com 
economic status use the activities of leisure time (3). Recreational sports or sports related to leisure time are the most appropriate and necessary ways for spending leisure time in present era; however, recreational sports (also called leisure time) include those activities whose aim of first physical health, compensation of kinetic deficiencies and enjoying sport (4). The role of physical activity in daily life and individuals' health is not hidden on anyone; thus, identification of effective factors on attraction of individuals on sport arenas is very important (5). One place to achieve mental peace, perform physical activity and spend leisure time is park that could create a place free of tension and anxiety for different people in society. Since parks are public places, they could provide various opportunities for physical activity; however, concerning little information on the relation between environmental features of parks and physical activities, many aspects of such places should be studied (6). White et al. (2016) stated that Natural environments provide the context for a large proportion of England's recreational physical activity and highlight the need to protect and manage such environments for health purposes (7). Now, concerning the role of parks in individuals' life generally, and their role on physical activities specifically; it could be said that for design and construction of these places, various features should be considered with highest effect on individuals for attendance in these places and dealing with sport activities. Thus, diagnosis of these features seems to be very significant.

Many studies with the different variables and title have been done on sport spaces and parks some of which will be discussed here. Esmaeilzadeh (2011) showed that the main reason for people attendance in parks is entertainment and physical activity and also the general view, accessibility, security, managerial strategies, beauty, maintenance status and socioeconomic situation in individuals' attendance in park is for the purpose of physical activity and entertainment (8). Crombie et al. (2004), in their study used the geographical data system and concluded that the most important barrier in dealing with sport in leisure time is lack of interest. They declared that accessibility of facilities is required for encouraging people in physical activity (9). Moore et al. (2008) showed that the spatial distribution and dispersion of resources and recreational equipment have been unequally distributed among various levels of areas with low income and different racial condition. At the end, they proposed that it is possible to increase physical activity with development of various types of parks and the quality of their equipment and decrease the immobility of people in society (10). Mc Cormack et al. (2010) concluded that some environmental features such as security, facilities, maintenance and closeness of main factors are effective in encouraging the use of parks and performing physical activity (11). Rohodes et al. (2007) showed that the selection of walking as an activity in leisure time has no relation with class level (12). Stronegger et al. (2010) showed that the social relation and accessibility to environmental facilities and leisure time facilities have been mainly associated with satisfaction and physical activity behavior (13).

Kaczynski and Mowen (2010) showed that the security of neighborhood area and its beauty as predicting factors of physical activity have meaningful levels in some parks and at the end, the significance of green space and park showed correlation with increased occurrence of physical activity (14). Concerning the objective measurement obtained concerning the effect of environmental symbols on physical activity of young boys, Timperior et al. (2007) showed that designing of neighborhood area with high quality leads to more physical activity (15).

Now, concerning what was mentioned and since parks and its diverse spaces are the most important for recreation and entertainment. It seems that environmental features have some effects on attraction of people and their attendance in parks for spending leisure time especially physical activities. Performing such studies concerning the people opinion on the use of parks and the role of their environmental features on spending leisure time make it necessary for the authorities to use the results of studies for development of these spaces. Thus, the aim of present study was to investigate the role of environmental features of parks in activation of recreational activities at leisure time of people living in Pakdasht city. 


\section{MATERIALS AND METHODS}

The present study is descriptive analytical that is practical in terms of objective and field study in terms of data collection.

Participants. The statistical population of the study includes all parks of Pakdasht city out of which 6 samples have been taken into account concerning the geographical distribution and the sample of people attending to the parks was estimated using Cochran formula with reliability coefficient of 0.95 and estimation precision of 0.03 as 382 members that increased to 477 subjects by applying $25 \%$ coefficient (number of samples increased Due to enough returned questionnaires) and ultimately 425 questionnaires was used.

Measurements. For data collection, Made Questionnaire adapted from Bedimo-Rung, 2005 (16), Kaczynski, 2007 and Cohen, 2007 (17) has been used with dimensions of design, beauty, green space, accessibility, pedestrian path, the location, traffic expectations, security, facilities and equipment, management (policy), socioeconomic status after reliability and validity confirmation (Cronbach alpha, 0.96).

Statistical Analysis. For data analysis, descriptive and referential statistics (path analysis and structural equation model and multivariate regression analysis) have been used.

\section{RESULTS}

The structural equations model (figure 1) indicates meaningful relation between design, green space, accessibility, Placement, beauty, traffic expectation, security and management. The coefficient of design path on recreational activity is 0.14 , the coefficient of green space path on recreational activity is 0.21 , the coefficient of accessibility path on recreational activity is 0.17 , the coefficient of the location path on recreational activity is 0.21 , the coefficient of beauty path on recreational activity is 0.18 , the coefficient of traffic expectation path on recreational activity is 0.14 , the coefficient of security on recreational activity is 0.17 , the coefficient of management path on creational activity is 0.22 . Briefly, concerning the fact that the significance level of these variables has been above 1.96 (figure 2), thus, the variables of design, green space, accessibility, location, beauty, traffic expectation, security and management have meaningful relation with attendance and attraction of users of parks for recreational activity. Moreover, in testing relations using structural equations model, first, the software output indicates the appropriate fitted structural model for testing hypotheses (the ratio of Chisquared to $\mathrm{df}$ is below 3); thus, Chi2 value is appropriate and low value. Moreover, ARMSE $=0.044$ indicates the goodness of fit of structural model.

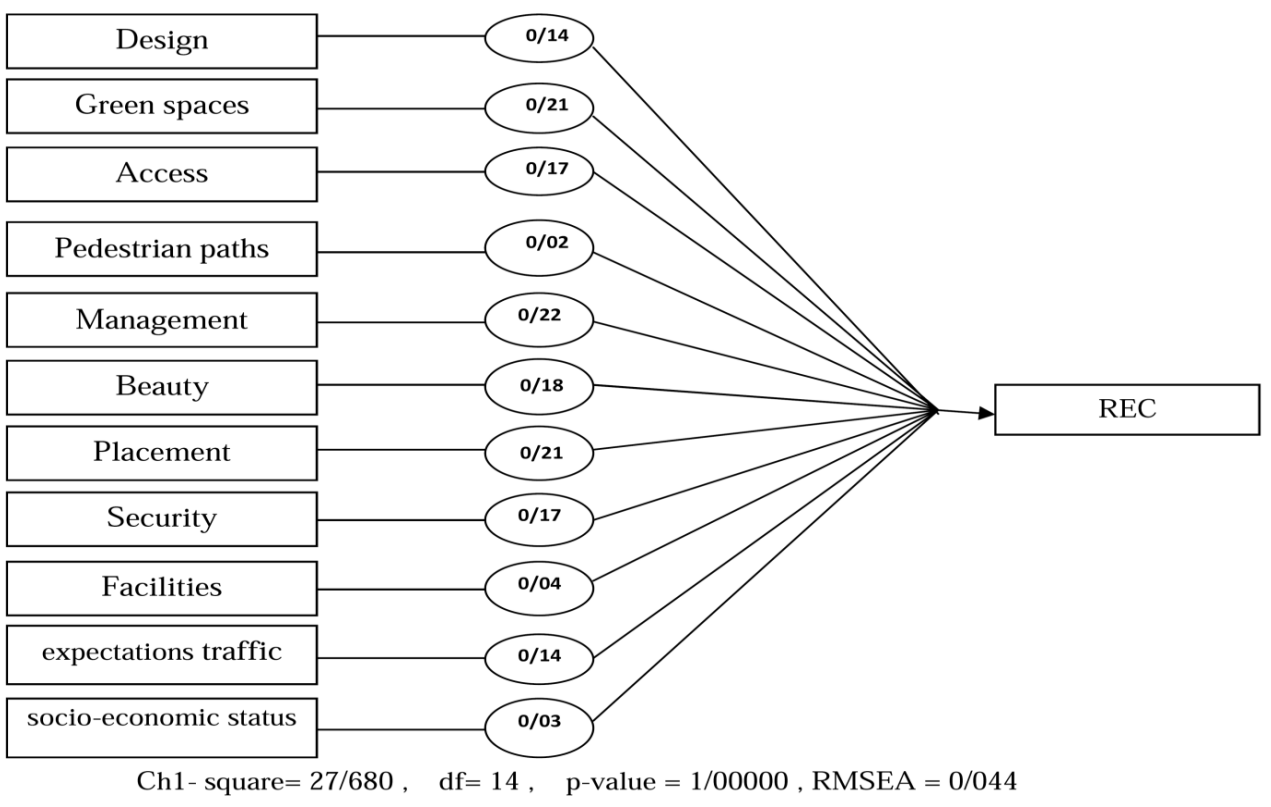

Figure1. The structural equations model of the effect of independent variables on the attendance for recreational activity in meaningful level 


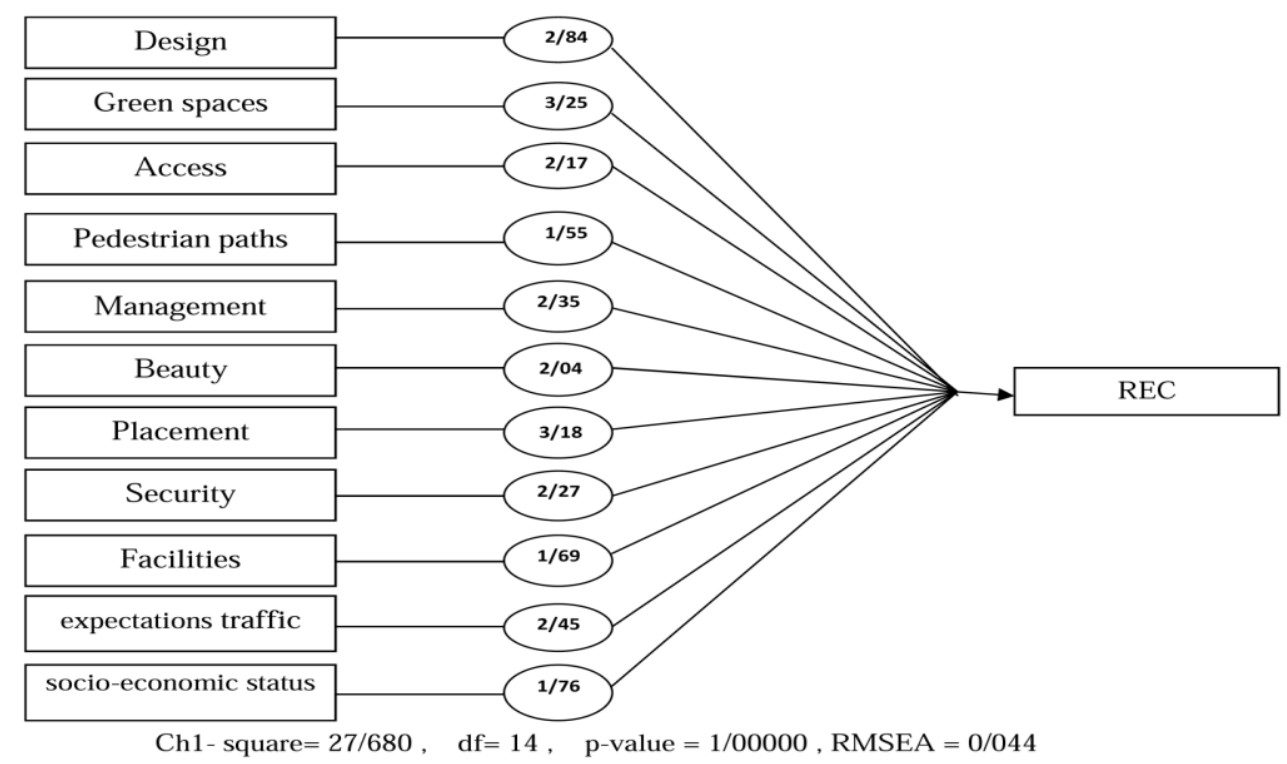

Figure2. The structural equations model of the effect of independent variables on the attendance for recreational activity in $T$-Value level

As can be observed in table 1, all indices of model fitness benefit from appropriate value. Thus, it could be said that the main research models have relatively good fitness and are accepted. As it was expressed, Chi2 to df ratio should be below 3; ARMSE index should be maximum 0.08 and the GIF, AGFL, NFI should be bigger than 0.90 ; moreover, all indices indicate appropriate model.

Table 1. The fitness indices of path analysis of recreational activity

\begin{tabular}{cccccc}
\multirow{2}{*}{ Fitness indices } & $x^{2} / \mathrm{d} f$ & ARMSE & GIF & AGIF & NFI \\
\cline { 2 - 6 } & 1.97 & 0.044 & 0.90 & 0.92 & 0.91 \\
\hline
\end{tabular}

Since the significance level of variables of pedestrian path, equipment and socioeconomic status is more than 0.05 . Thus, the assumption of equality of the constant value and zero value is confirmed and leave regression equation (Table 2).

Moreover, since the significance level of coefficients of design, green space, accessibility, location, beauty, traffic expectation, security and management is less than 0.05 , the assumption of equality of coefficients with constant value is rejected and it is not needed to exclude them from regression equation. In other words, the research variables except pedestrian path, facilities and socioeconomic status have meaningful relation with attendance and attraction of people to park for sport activity during the week. For comparison of the effects of independent variables in regression model on dependent variable, just standardized coefficients are used such that the effect of accessibility on dependent variable (attendance for recreational activity) is more than other variables and concerning the table, the value of standardized coefficients obtained from SPSS is equal to model in standard estimation status in linear structural relations (LISREL) software.

\section{DISCUSSION}

Concerning research findings, there is positive meaningful relation between age group and attendance of users in parks at leisure time for performing sport activity during the week. This finding is in line with the results of Esmaeilzadeh (2011), Jago (2005) (18), Riva (2007) (19) who observed the relation between age group and attendance and attraction of people to parks at leisure time for sport activity. What the other matching studies proposed is the presence of sport equipment in parks (19) and more pedestrian path that could lead to increased sport activity especially for elderlies (18). 
Table 2. The comparison of the effects of independent variables in regression model on the attendance in park for recreational activity

\begin{tabular}{cccccc}
\hline Model & $\mathrm{t}$ & $\begin{array}{c}\text { Standard effect } \\
\text { coefficient }\end{array}$ & \multicolumn{2}{c}{$\begin{array}{c}\text { Non-standard effect } \\
\text { coefficient }\end{array}$} & Significance coefficient \\
\hline 1 (constant) & 1.564 & 0.166 & 1.767 & 2.785 & 0.125 \\
\hline Design & 2.765 & 0.213 & 0.278 & 0.789 & 0.05 \\
\hline Green space & 2.456 & 0.169 & 0.245 & 0.879 & 0.013 \\
\hline Accessibility & 3.239 & 0.223 & 0.304 & 0.945 & 0.003 \\
\hline Pedestrian path & 1.697 & 0.021 & 0.327 & 0.189 & 0.253 \\
\hline Location & 2.345 & 0.158 & 0.358 & 0.702 & 0.031 \\
\hline Beauty & 2.367 & 0.132 & 0.369 & 0.874 & 0.014 \\
\hline Traffic expectation & 2.487 & 0.145 & 0.367 & 1.456 & 0.019 \\
\hline Security & 2.487 & 0.145 & 0.367 & 1.456 & 0.019 \\
\hline Facilities and equipment & 1.625 & 0.017 & 0.324 & 0.193 & 0.424 \\
\hline Management & 2.351 & 0.216 & 0.349 & 0.557 & 0.041 \\
\hline Economic status & 1.346 & 0.016 & 0.318 & 0.176 & 0.563 \\
\hline
\end{tabular}

Concerning research findings, there is no meaningful relation between the income and the attendance in part for recreation. Craige et al. (2002) believes that there is no meaningful relation between income and environmental factors and walking to workplace (20). On the other hand, the annual income of family for performing sport activity has been recommended. These findings are consistent with the results of Esmaeilzadeh (2011), Sugiyama and Thompson (2008) (21) and Suminski et al. (2005) (22).Concerning research findings; it seems that increased safety of environment and the instrument leads to increased use and presence of women or kids. There is some relation between recreational activities at leisure time and traffic expectations of parts in attendance and attraction of users in parks. These findings are consistent with the results of Cerin and Leslie (2008) (23) and Dalman and Lewis (2010) (24) studies and according to definition, traffic expectation means consideration of a space for parking (automobile, motorcycle and bicycle). Ball et al. (2001) believes that the park's surrounding area and the spread of park with consideration of streets and traffic to park and green spaces for recreational activities require some space for vehicles and has correlation with performing sport activity (25). Concerning research findings, it seems that the satisfaction of people in use of parks and interaction and relation of attendants with each other in traffic and cooperation with traffic police in facilitation of traffic have significant effect on decreasing traffic in parks' neighborhood areas. There is no relation between recreational activities in leisure time and facilities of parks in attraction and attendance of individuals to parks. Humpel et al. (2004) believes that maintenance of various vehicles in parks and various spaces in terms of standardization, security, maintenance, repair and cleanness have effective role in attraction of people (26). The bigger area of parks and recreational areas could be effective on the use of individuals' of the facilities, various spaces of park and consequently sport activity (27). Concerning research findings, it seems that the authorities of parks and recreational and sport centers should improve the environmental condition of these centers including bodybuilding devices, designing of training sections, advanced and safe facilities. Crompton (2003) believes that park management and its functional policies in public places, especially parks, includes programming, timing and control and some other items such as the presence of full time employees in recreational centers and special programs for youth (28). Moreover, managerial and environmental strategies for more use of public places (29) and structural changes and programs in the parks with special view of youth and women could be effective on the individuals' attendance to park, sport or recreational games (30). Any region could lead to development of accessibility to place and increased sport activity based on designing of environment and its managerial strategies (31). 
Concerning research findings, it can be concluded that sport activity in park is influenced by park management. Moreover, management of public green spaces leads to increased presence of elderlies and recreational activity by creating natural symbols and social interactions. There is no relation between recreational activities at leisure time and socioeconomic status of parks' neighborhood areas on attendance of individuals in parks. Van Lenthe et al. (2004) believe that the differences in socioeconomic status of neighborhood area could lead to difference in mobility and sport activity; however, the direction of this difference differs for various groups (32). For example, areas with weaker socioeconomic status show less sport activity; however, environmental features could decrease this correlation. Usually, the inhabitants of areas with low income have less sport activity and this might be due to the problem of accessibility to park or other recreational arenas (33).

\section{CONCLUSION}

Concerning research findings, it could be concluded that the prosperity and welfare of neighborhood area, the individual's income and occupational status are among effective factors in this variable. Moreover, the better socioeconomic status of park's surrounding area and the population living in that environment has more cumulative effect on the individuals' viewpoint toward sport and recreational activity at leisure time. Moreover, to get satisfaction of the audiences, parks should perform the required feasibility and polling and increase the attraction of attendants by development of their health. Thus, concerning research findings, it is proposed that parks and green spaces that attract walking trips should not be located beside highways which have high allowed speed since it increases the risk of passengers' accident. Concerning the recreational programs and services, the authorities and programmers should plan such that the expectations and demands of attendants and use of these services are fulfilled and their satisfaction of referring to these places achieves the highest level.

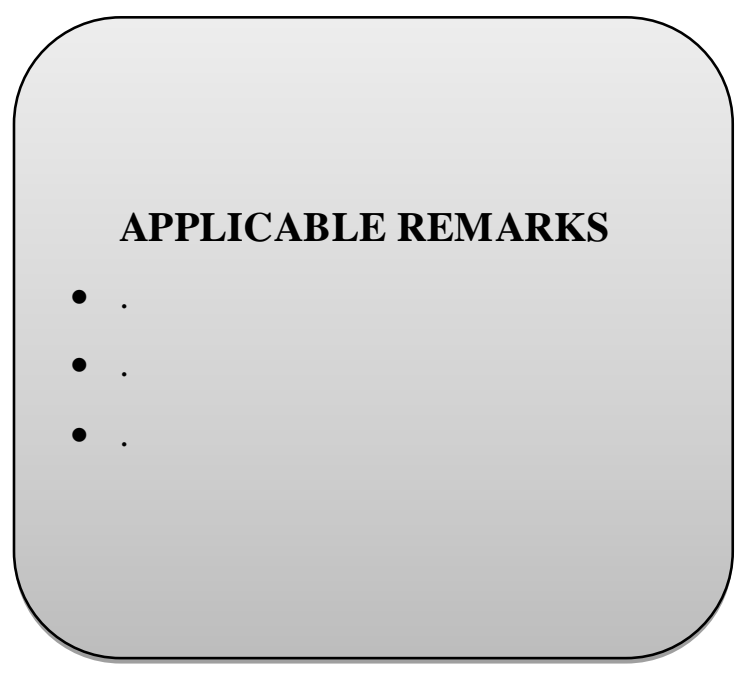

\section{REFERENCES}

1. Falahat MS, Kalami M. The effect of urban open spaces on the quality of spending leisure time of citizens. Journal of urban management. 2008; 22(4): 85-98.

2. Santos T, Nogueira Mendes R, Vasco A. Recreational activities in urban parks: Spatial interactions among users. Journal of Outdoor Recreation and Tourism. 2016; . http://dx.doi.org/10.1016/j.jort.2016.06.001i

3. Roberts, Ken. Leisure: the importance of being inconsequential. Leisure studies. 2011; 30(1): 5-20.

4. Jalali Farahani, M. Management of leisure time and recreational sports. 1nd ed: University of Tehran Publication, Tehran. pp. 2011; 61-80.

5. Zohrevandian K, Ebrahimi F. Presenting the proposed model for locating sport facilities using the combination of GIS and MCDM. Sport management studies. 2013; 5 (21): 111-126.

6. Bedimo-rung A L. environmental determinants of physical activity in parks; brat-direct observation reference manual, version: may 24, health sciences, new Orleans School of Public Health, Epidemiology. 2007; TrainingDO Manual-S2PK2-05-24-07.doc

7. White MP, Elliott LR, Taylor T, Wheeler BW, Spencer A, Bone A, Depledge MH, Fleming LE. Recreational physical activity in natural environments and implications for health: A population based cross-sectional study in England. Preventive Medicine.2016; (91) 383-388

8. Esmaeilzadeh Qandehari M R. The role of environmental features of parks (FASPEC) in activation of leisure time and presenting management of optimum use pattern. PhD thesis, Faculty of Physical Education and Sport Sciences. Islamic Azad University, Tehran Central Branch. 2011. 
9. Crombie IK., Linda I, Brian W, Alison R, Mc Ginnis, Peter W, Slane E M. Marion ET, Murdo Mc. Why older people do not participate in leisure time physical activity: A survey of activity levels. Beliefs and Deterrents. 2004; 33(3):287-292

10. Latetia V M, Diez R, Ana V, Evenson K R, Mc Ginn, A P, Brines S J. Availability of Recreational Resources in Minority and Low Socioeconomic Status Areas. American journal of Preventive medicine. 2008; 34(1): 16-22

11. Mc Cormack G, Annam M, Danica H T. characteristics of urban parks associated with park use and physical activity: a review of qualitative research. Health \& place. 2010; 16(4): 712-726.

12. Rohodes R E, Courneya K S, Blandchard C M, Platnikaf R C. predication of leisure time walking: an integration of social cognitive, perceived environmental, and personality factors. International journal of behavioral nutrition and physical activity. 2007; doi:10,11 86/1479-5868-4-51.

13. Stronegger W J, Titze S, Oja p. Perceived characteristics of neighborhood and association with physical activity behavior and self-rated health. journal of health\& place. 2010; 16(4): 736-743.

14. Kaczynski a, mowen a j. Does self- selection influence the relationship between park availability and physical activity preventive medicine. 2010; 52(1),23-25.

15. Timperior a, ball $\mathrm{k}$, salmon $\mathrm{j}$, Robert $\mathrm{r}$, crowford $\mathrm{D}$. is availability of public open space equitable across areas? Journal of health\& place. 2007; 13(2):335-340.

16. Bedimo-rung AL, Mowen AJ, Cohen DA. the significance of parks to physical activity and public health. American journal of preventive medicine. 2005; 28(2s2):152-168.

17. Cohen DA, mckenzie T., sehgal A, Williamson S, golinelli D, lurie N. contribution of public parks to physical activity. American journal of public health. 2007; 97(3):509-514.

18. Jago R, Baranowski T, Zakeri T, Harris M. observed environmental features the physical activity of adolescent males. American journal of preventive medicine. 2005; 29(2): 98-104.

19. Riva M, Gauvin L, Richard L. Use of local area facilities for involvement in physical activity in Canada: insight for developing environmental and policy intervention. Health Promotion International. 2007; 22 (3): 227- 235.

20. Craig CL, Brownson RC, Cragg SE, Dunn AL. Exploring the effect of the environment on physical activity: a study examining walking to work". American Journal of Preventive Medicine. 2002; 23(2 Supp 1):36-43

21. Sugiyama T, Thompson CW. association between characteristics of neighborhood open space and older peoples walking. Journal of urban forestry \& urban greening. 2008; 7(1): 41-51.

22. Suminski RR, Poston WS, Petosa RL, Stevens E, Katzenmoyer LM. Features of the neighborhood environment and walking by U.S. adults. American journal of preventive medicine. 2005; 28(2):149-55.

23. Cerin E, leslie E. How socio- economic status contributes to participating in leisure time \& physical activity. Journal of social science \& medicine. 2008; 66(12): 2596-2609.

24. Dollman J, Lewis NR, The impact of socioeconomic position on sport participation among South Australian youth. Journal of Science and Medicine in Sport. 2010; 13(3):318-322

25. Ball K, Bauman A, Leslie E, Owen N. Perceived Environmental Aesthetics and Convenience and Company Are Associated with Walking for Exercise among Australian Adults. journal of Preventive Medicine. 2001; 33(5): 434-440

26. Humpel N, Owen N, Iverson D, Leslie E, Bauman Ad. Perceived environment attributes, residential location, and walking for particular purposes. American Journal of Preventive Medicine. 2004; 26(2): 119-125

27. Roemmich J N, Epstein LH, Samina R, Yind L, Robinson J, Winiewicz D. Association of access to parks and recreational facilities with the physical activity of young children. journal of Preventive Medicine. 2006; 43(6):437-41

28. Crompton JL. Strategies for implementing repositioning of leisure services. managing Leisure. 2009; 14(2): 87 111.

29. Moody JS, Prochaska JJ, Sallis JF, McKenzie TL, Brown M, Conway TL. Viability of parks and recreation centers as sites for youth physical activity promotion. Health Promot Pract. 2004; 5(4): 438-443.

30. Tester J M, Baker R. Making the playfields even: Evaluating the impact of an environmental intervention on park use and physical activity. University of California, Berkeley, School of Public Health, USA. journal of Preventive Medicine. 2009; 48(4):316-320.

31. Panter J, Jones A, Hillsdon M. Equity of access to physical activity facilities in an English city. Journal of Preventive Medicine. 2008; 46(4): 303_307

32. van Lenthe FJ, Brug J, Mackenbach JP. Neighborhood inequalities in physical inactivity: the role of neighborhood atractiveness, proximity to local facilities and safety in the Netherlands. Social Science \& Medicine. 2005; 60(4): 763-775

33. Floyd MF, Bocarro J.N, Thompson TD. Research on race and ethnicity in leisure studies: A review of five major journals. J. Leis. Res. 2008, 40, 1-22. 